\section{Analysis of Genetic Parameters of Habanero Pepper (Capsicum chinense Jacq.) in the Yucatan, Mexico}

Laura P. Peña-Yam, Liliana S. Muñoz-Ramírez, Susana A. Avilés-Viñas Adriana Canto-Flick, Jacobo Pérez-Pastrana, Adolfo Guzmán-Antonio, and Nancy Santana-Buzzy ${ }^{1}$

Unidad de Bioquímica y Bilogía Molecular de Plantas, Centro de Investigación Científica de Yucatán (CICY), Calle 43 No. 130, Chuburná de Hidalgo, Mérida, Yucatán, CP 97205, México

\section{Erick A. Aguilera-Cauich and Javier O. Mijangos-Cortés Unidad de Recursos Naturales, Centro de Investigación Científica de Yucatán (CICY), Mérida, Yucatán, México}

Additional index words. heritability, genetic improvement, hybrid production, germplasm resources

\begin{abstract}
The variability and genetic parameters of seven agronomic characteristics were estimated for 11 genotypes, and high values of the phenotypic coefficient of variation (PCV) of capsaicin content (CC) were obtained. Heritability $\left(h^{2}\right)$ was high for yield per plant (YP; 0.98) and CC (0.93). The principal components analysis (PCA) revealed that the first three components explained $94.02 \%$ of the total variation; therefore, genotypes with higher YP values and fruit weight (FW) (AKN-08, ASBC-09) were placed in quadrant I. Those with greater CC and lowest YP and FW (MBI-11, RES-05) were placed in quadrant II. The greatest fruit length (RNJ-04) was placed in quadrant III. Those with the greatest number of fruits per plant (NBA-06, RKI-01, RHC-02, RHN-03, NKA-07, and MSB-12) were placed in quadrant IV. The results showed that the genotypes studied comprise an excellent source of genetic material for Habanero pepper improvement programs.
\end{abstract}

The genus Capsicum includes diverse peppers and chilies, which are the most consumed vegetables in the world. Mexico has the greatest genetic diversity of this plant genus. Capsicum comprises a complex taxa (species and varieties) exhibiting high genetic and phenotypic diversity. There are 32 described taxa, of which five are considered to be domesticated: $C$. annuum L. (Bell pepper, Jalapeños), $C$. frutescens L. (Tabasco variety), $C$. chinense Jacq. (Habanero pepper and Scotch Bonnet), C. baccatum (Aji variety), and $C$. pubescens L. (Rocoto and Manzano varieties) (Baba et al., 2016). Habanero pepper (Capsicum chinense Jacq.) is one species within this genus that has the highest market demand, and it is one of the hottest chilies in the world.

The Mexican Habanero pepper can be distinguished from the Habanero pepper grown in any other region of the world by its aroma, flavor, and its particularly high degree of heat. Because of these attributes, the Habanero pepper of the Yucatan Peninsula was granted the Denomination of Origin in 2010 (DOF, 2012). The Habanero pepper of the Yucatan Peninsula is charac-

Received for publication 30 Oct. 2018. Accepted for publication 17 Dec. 2018.

${ }^{1}$ Corresponding author. E-mail: buzzy@cicy.mx. terized by its great diversity in shapes and colors. However, the absence of improved varieties has been one of the factors influencing the slow development of the crop in the region.

Precise estimates of genetic parameters, such as the components of variance and narrow-sense heritability for economically important population characteristics in breeding programs, allow us to calculate optimal selection rates, maximize genetic gain rates, and choose the most appropriate selection system (Silva-Cifuentes et al., 2011). The extent of genetic variability is of paramount importance for crop improvement because greater genetic variability in the existing germplasm would allow the selection of superior genotypes (Bhatia et al., 2017). Genetic variability has been studied and different genetic parameters have been estimated for other species, but not for $C$. chinense Jacq. (Mishra et al., 2015; Mehmood et al., 2014; Saoudi et al., 2016; Sieczko et al., 2015; Tripathi et al., 2012, 2013).

The aim of the present work was to evaluate and select outstanding progenitors of Habanero pepper for their agricultural yield and high capsaicin content (CC) based on the heritability index and genetic variability to incorporate them in a cross-breeding program to obtain F1 lines with high productive potential and increased pungency.
An evaluation of 11 genotypes from the germplasm of C. chinense Jacq. conserved in the Scientific Research Center of Yucatan, Mexico, was performed (Table 1). The evaluation was conducted in the greenhouses of the seed production unit at the Scientific and Technological Park of Yucatan, which is located in Sierra Papacal, Merida, Yucatan, at lat. $21^{\circ} 07^{\prime} 20^{\prime \prime} \mathrm{N}$, long. $89^{\circ} 43^{\prime} 41^{\prime \prime} \mathrm{W}$ at an altitude of $9 \mathrm{~m}$ above sea level, from Sept. 2016 to June 2017.

An experimental design involving completely randomized blocks with four repetitions was used. Agronomic management was conducted in the following manner: the transplant was performed in growbags (Pelemix, Guadalajara Jalisco, Mexico) with a length of $1 \mathrm{~m}$. Coconut fiber (thick and fine) in a proportion 70:30 was used as substrate; the distances between plants and rows were 20 $\mathrm{cm}$ and $160 \mathrm{~cm}$, respectively. Eight plants of each genotype per block were evaluated during the third and fourth harvest, and the morphological characterization of the fruit was based on the descriptors for the genus Capsicum (IPGRI, 1995). The characteristics that were evaluated were fruit weight $(\mathrm{FW}$; $\mathrm{g})$, pericarp thickness $(\mathrm{PT} ; \mathrm{cm})$, fruit length $(\mathrm{FL} ; \mathrm{cm})$, fruit width (WF; $\mathrm{cm})$, number of fruits per plant (NFP), and yield per plant (YP; g/plant). In addition, CC was determined $\left[\mathrm{mg} \cdot \mathrm{g}^{-1}\right.$ of dry weight (DW)] using the method of Collins et al. (1995) and quantified by high-performance liquid chromatography.

Data were subjected to an analysis of variance (ANOVA) test and Tukey's test of comparison of means $(P \leq 0.05)$ using the SAS program version 9.1 for Windows (SAS Institute, Inc., 2003). The association between characteristics was determined using Pearson correlations and the IBM statistical program SPSS Statistics version 22 (IBM Corp., 2013). The average values of the data from the characteristics evaluated were subjected to a PCA and a hierarchical cluster analysis using the Euclidean distance and Unweighted Pair Group Method with Arithmetic Mean (UPGMA) ligation algorithm as a dissimilarity index for which the statistical package NTSySpc 2.2 (Rohlf, 2005) was used. The following genetic parameters were determined: variances and coefficients of variation (genotypic, phenotypic, and environmental), as well as heritability in a broad sense $\left(\mathrm{h}^{2}\right)$, according to the methodology reported by Pistorale et al. (2008):

Variances.

Genetic variance $\left(\sigma_{G}^{2}\right)=\mathrm{MS}_{\mathrm{g}}-\mathrm{MS}_{\mathrm{e}} / \mathrm{r}$

Environmental variance $\left(\sigma_{E}^{2}\right)=\mathrm{MS}_{\mathrm{e}}$

Phenotypic variance $\left(\sigma_{P}^{2}\right)=\sigma_{G}^{2}+\sigma_{E}^{2}$

where $\mathrm{MS}_{\mathrm{g}}=$ mean square of the genotypes, $\mathrm{MS}_{\mathrm{e}}=$ mean square of the experimental error, and $\mathrm{r}=$ number of repetitions. 


\section{Coefficients of variation.}

Genotypic coefficient of variation $(\mathrm{GCV})$

$$
=\sqrt{\frac{\sigma^{2}{ } \times 100}{\bar{\chi}}}
$$

Phenotypic coefficient of variation $(\mathrm{PCV})$

$$
=\sqrt{\frac{\sigma_{p}^{2} \times 100}{\bar{\chi}}}
$$

Environmental coefficient of variation

$$
\begin{aligned}
(\mathrm{ECV}) & =\sqrt{\frac{\sigma^{2}{ }_{E} \times 100}{\bar{\chi}}} \\
\bar{\chi} & =\text { mean of each variable. }
\end{aligned}
$$

\section{Heritability.}

$$
\text { Heritability }\left(h^{2}\right)=\sigma_{G}^{2} / \sigma_{P}^{2}
$$

where $\sigma_{P}^{2}=\sigma_{G}^{2}+\sigma_{E}^{2}$

Genetic advances (GA) and GA as the mean percentage ( $\% \mathrm{GA}$ of the mean) were estimated in accordance with the work of Acquaah (2009):

$$
A G=i h^{2} \sigma
$$

where 2.06 at $5 \% ; \mathrm{h}^{2}=$ heritability; $\sigma=$ phenotypic variation.

$\%$ GA of the mean $=(\mathrm{GA} / \bar{\chi}) \times 100$

where $\bar{\chi}=$ mean of each variable.

\section{Results}

The ANOVA revealed significant differences in quantitative traits of the 11 varieties, thus indicating the existence of variability among the varieties of the studied characteristics (Table 2). The analysis of the means among the genotypes and of the different characteristics indicated that genotype ASBC-09 differed significantly from the other genotypes evaluated for the same characteristics: WF was $4.32 \mathrm{~cm}(P=0.000)$ and YP was $2610.28 \mathrm{~g} /$ plant $(P=0.000)$ (Table 3). The genotypes of yellow fruit, ASBC-09 and AKN-08, had higher FW (16.82 $\mathrm{g}$ and $16.68 \mathrm{~g}$, respectively) without deferring one from the other $(P=1.00)$. Genotype RES-05 presented the highest CC (147.11 mg.g $\left.{ }^{-1} \mathrm{DW}\right)$. As a result, a wide range of variation was obtained in the values of CV (14.08\%-94.50\%) for all characteristics evaluated. The highest values corresponded to CC $(94.50 \%)$ and NFP $(27.52 \%)$, whereas the lowest values were for FL $(14.08 \%)$ and WF (15.99\%) (Table 2).

Variability, heritability, and genetic advance. The results of the variability analysis in terms of range, general average, variances (genetic, phenotypic, and environmental); coefficients of variation: genotypic (GCV), phenotypic (PCV), and environmental (ECV); heritability in a broad sense $\left(h^{2}\right)$, genetic advance (GA), and genetic advance as percentage of mean, are shown in Table 4. A maximum range of variation was observed for
YP (1772.38 g/plant), followed by NFP and $\mathrm{CC}$, with values of 163 and $138.60 \mathrm{mg} \cdot \mathrm{g}^{-1}$ DW, respectively. The characteristics with the lowest ranges of variation were registered for PT $(0.15 \mathrm{~cm})$, FL $(2.16 \mathrm{~cm})$, and WF $(2.10$ $\mathrm{cm})$. Estimates of the GCV and PCV were higher for CC $(29.45 \%$ and $30.40 \%$, respectively) and NFP $(8.53 \%$ and $9.25 \%$, respectively) (Table 4).

The high heritability obtained for YP (0.98), CC (0.93), FW (0.91), and NFP (0.85) were noteworthy (Table 4). High heritability was also observed in conjunction with high \%GA of the mean for these same characters.

Correlations analysis. The direction and magnitude of the phenotypic association of the different characteristics analyzed indicated that YP was positively correlated with PT $\left(0.770^{* *}\right)$ and with WF $\left(0.519^{* *}\right)$ (Table 5). This result indicated that fruits with thick pericarp have high yield. The $\mathrm{CC}$ presented a correlation inversely proportional with YP $\left(-0.883^{* *}\right)$ and PT $(-0.744)$, from which we can infer that the genotypes with a higher CC (RNJ-04 and RES-05) present lower yield and reduced PC. FW was positively correlated with WF $(0.662 * *)$ and $\mathrm{YP}\left(0.558^{* *}\right)$, indicating that the genotypes with greater yield (ASBC-09 and $\mathrm{AKN}-08$ ) presented the highest FW and the greatest WF, whereas WF presented an inversely proportional correlation with FL $\left(-0.573^{* *}\right)$.

Principal components analysis. The results of the PCA (Table 6) showed that the first three components $(\mathrm{C} 1, \mathrm{C} 2$, and $\mathrm{C} 3)$ extracted $94.02 \%$ of the total variation. The first component $(\mathrm{C} 1)$, with $53.03 \%$ of the total variation, was mainly determined by

\begin{tabular}{|c|c|c|c|c|}
\hline \multirow[b]{4}{*}{ Characteristics } & \multicolumn{3}{|c|}{ Mean squares } & \multirow[b]{4}{*}{$\mathrm{CV} \%$} \\
\hline & Replication & Genotype & Error & \\
\hline & \multicolumn{3}{|c|}{$\mathrm{df}$} & \\
\hline & 3 & 10 & 30 & \\
\hline$\overline{\mathrm{FW}}(\mathrm{g})$ & 0.011 & $44.64 *$ & 0.10 & 27.19 \\
\hline PT $(\mathrm{cm})$ & 0.000 & $0.007^{*}$ & 0.00 & 18.93 \\
\hline $\mathrm{FL}(\mathrm{cm})$ & 0.008 & $1.57^{*}$ & 0.01 & 14.08 \\
\hline $\mathrm{WF}(\mathrm{cm})$ & 0.023 & $1.08 *$ & 0.01 & 15.99 \\
\hline NFP & 30.60 & $10,725.27^{*}$ & 42.77 & 27.52 \\
\hline YP (g/plant) & 567.14 & $1,331,868.34^{*}$ & 597.15 & 26.50 \\
\hline $\mathrm{CC}\left(\mathrm{mg} \cdot \mathrm{g}^{-1} \mathrm{DW}\right)$ & 0.009 & $7,949.15^{*}$ & 11.89 & 94.50 \\
\hline
\end{tabular}
the variables PT, YP, and CC. The second component (C2) extracted $24.79 \%$ of the total

Table 1. Characteristics associated with the fruit of 11 genotypes of Capsicum chinense Jacq.

\begin{tabular}{lccll}
\hline Genotype & Color in immature state & Color in mature state & Shape of fruit & Type of Epidermis \\
\hline RKI-01 & Light green & Red & Triangular & Smooth \\
RHC-02 & Light green & Red & Campanulate & Smooth \\
RHN-03 & Dark green & Red & Triangular & Smooth \\
RNJ-04 & Dark green & Red & Triangular & Strongly wrinkled \\
RES-05 & Light green & Red & Square & Strongly wrinkled \\
NBA-06 & Dark green & Orange & Triangular & Smooth \\
NKA-07 & Dark green & Orange & Triangular & Smooth \\
AKN-08 & Dark green & Yellow & Square & Smooth \\
ASBC-09 & Dark green & Yellow & Campanulate & Slightly wrinkled \\
MBI-11 & Dark green & Grey purple & Rectangle & Smooth \\
MSB-12 & Dark green & Grey purple & Campanulate & Slightly wrinkled \\
\hline
\end{tabular}

Table 2. Analysis of variance of the seven characteristics evaluated in 11 genotypes of $C$. chinense Jacq.

*Significant difference $(P \leq 0.05)$.

$\mathrm{df}=$ degrees of freedom; $\mathrm{CV} \%=$ percentage of coefficient variation; $\mathrm{FW}=$ fruit weight $\mathrm{PT}=$ pericarp thickness; $\mathrm{FL}=$ fruit length; $\mathrm{WF}=$ fruit width; $\mathrm{NFP}=$ number of fruits per plant; $\mathrm{YP}=$ yield per plant; $\mathrm{CC}=$ capsaicin content.

Table 3. Mean of the seven characteristics evaluated in 11 genotypes of $C$. chinense Jacq.

\begin{tabular}{lclllllc}
\hline Genotype & FW $(\mathrm{g})$ & PT $(\mathrm{cm})$ & FL $(\mathrm{cm})$ & WF $(\mathrm{cm})$ & NFP & YP $(\mathrm{g} / \mathrm{plant})$ & CC $\left(\mathrm{mg} \cdot \mathrm{g}^{-1} \mathrm{DW}\right)$ \\
\hline RKI-01 & $14.11 \mathrm{~b}^{\mathrm{z}}$ & $0.220 \mathrm{~cd}$ & $4.90 \mathrm{~b}$ & $3.01 \mathrm{~cd}$ & $170 \mathrm{ed}$ & $2,393.75 \mathrm{~cd}$ & $23.68 \mathrm{de}$ \\
RHC-02 & $12.73 \mathrm{c}$ & $0.193 \mathrm{e}$ & $4.32 \mathrm{c}$ & $3.14 \mathrm{c}$ & $184 \mathrm{~d}$ & $2,342.31 \mathrm{de}$ & $15.71 \mathrm{e}$ \\
RHN-03 & $9.75 \mathrm{de}$ & $0.239 \mathrm{bc}$ & $4.02 \mathrm{~d}$ & $2.81 \mathrm{~d}$ & $240 \mathrm{~b}$ & $2,276.00 \mathrm{f}$ & $20.34 \mathrm{de}$ \\
RNJ-04 & $6.75 \mathrm{~g}$ & $0.146 \mathrm{f}$ & $5.28 \mathrm{a}$ & $2.42 \mathrm{e}$ & $220 \mathrm{c}$ & $1,482.28 \mathrm{~g}$ & $120.38 \mathrm{~b}$ \\
RES-05 & $7.77 \mathrm{f}$ & $0.166 \mathrm{f}$ & $3.63 \mathrm{e}$ & $2.97 \mathrm{~cd}$ & $109 \mathrm{~g}$ & $846.78 \mathrm{i}$ & $147.11 \mathrm{a}$ \\
NBA-06 & $12.70 \mathrm{c}$ & $0.252 \mathrm{~b}$ & $4.81 \mathrm{~b}$ & $2.94 \mathrm{~cd}$ & $182 \mathrm{~d}$ & $2,315.25 \mathrm{ef}$ & $28.95 \mathrm{~d}$ \\
NKA-07 & $10.46 \mathrm{~d}$ & $0.227 \mathrm{c}$ & $5.03 \mathrm{ab}$ & $3.01 \mathrm{~cd}$ & $239 \mathrm{~b}$ & $2,501.32 \mathrm{~b}$ & $29.09 \mathrm{~d}$ \\
AKN-08 & $16.68 \mathrm{a}$ & $0.234 \mathrm{bc}$ & $4.48 \mathrm{c}$ & $3.67 \mathrm{~b}$ & $149 \mathrm{f}$ & $2,485.28 \mathrm{~b}$ & $26.52 \mathrm{~d}$ \\
ASBC-09 & $16.82 \mathrm{a}$ & $0.279 \mathrm{a}$ & $3.62 \mathrm{e}$ & $4.32 \mathrm{a}$ & $155 \mathrm{ef}$ & $2,610.28 \mathrm{a}$ & $23.82 \mathrm{de}$ \\
MBI-11 & $13.53 \mathrm{bc}$ & $0.198 \mathrm{de}$ & $4.24 \mathrm{~cd}$ & $2.95 \mathrm{~cd}$ & $105 \mathrm{~g}$ & $1,418.62 \mathrm{~h}$ & $44.54 \mathrm{c}$ \\
MSB-12 & $9.55 \mathrm{e}$ & $0.284 \mathrm{a}$ & $3.41 \mathrm{e}$ & $3.66 \mathrm{~b}$ & $256 \mathrm{a}$ & $2,448.01 \mathrm{bc}$ & $21.62 \mathrm{de}$ \\
\hline
\end{tabular}

${ }^{\mathrm{z}}$ Means within a column followed by the same letter are not significantly different at $P \leq 0.05$, by Tukey's Studentized range test.

$\mathrm{FW}=$ fruit weight $\mathrm{PT}=$ pericarp thickness $; \mathrm{FL}=$ fruit length; $\mathrm{WF}=$ fruit width; $\mathrm{NFP}=$ number of fruits per plant; $\mathrm{YP}=$ yield per plant; $\mathrm{CC}=$ capsaicin content. 
Table 4. Parameters of genetic variability of the seven characters evaluated in 11 genotypes of C. chinense Jacq.

\begin{tabular}{|c|c|c|c|c|c|c|c|c|c|c|c|}
\hline \multirow[b]{2}{*}{ Characteristics } & \multirow[b]{2}{*}{ Mean } & \multirow[b]{2}{*}{ Range } & \multicolumn{3}{|c|}{ Variance } & \multicolumn{3}{|c|}{ Coefficient of Variance } & \multirow{2}{*}{$\frac{\mathrm{h}^{2}}{\text { Broad sense }}$} & \multicolumn{2}{|c|}{ Genetic Advance } \\
\hline & & & Genetic & Phenotypic & Environmental & GCV (\%) & PCV (\%) & $\operatorname{ECV}(\%)$ & & GA & Mean GA $\%$ \\
\hline FW (g) & 11.90 & 10.50 & 1.01 & 1.12 & 0.10 & 8.46 & 8.88 & 2.71 & 0.91 & 2.09 & 17.53 \\
\hline PT $(\mathrm{cm})$ & 0.22 & 0.15 & 0.00016 & 0.00024 & 0.00008 & 5.79 & 7.01 & 3.96 & 0.68 & 0.0003 & 0.15 \\
\hline $\mathrm{FL}(\mathrm{cm})$ & 4.34 & 2.16 & 0.04 & 0.05 & 0.01 & 4.33 & 5.05 & 2.61 & 0.73 & 0.07 & 1.67 \\
\hline $\mathrm{WF}(\mathrm{cm})$ & 3.17 & 2.10 & 0.02 & 0.03 & 0.01 & 4.91 & 5.77 & 3.03 & 0.72 & 0.05 & 1.58 \\
\hline NFP & 182.64 & 163.00 & 242.78 & 285.56 & 42.77 & 8.53 & 9.25 & 3.58 & 0.85 & 500.14 & 273.84 \\
\hline YP (g/plant) & $2,101.81$ & $1,772.38$ & $30,256.16$ & $30,853.31$ & 597.15 & 8.28 & 8.36 & 1.16 & 0.98 & $62,327.70$ & $2,965.43$ \\
\hline $\mathrm{CC}\left(\mathrm{mg} \cdot \mathrm{g}^{-1} \mathrm{DW}\right)$ & 45.61 & 138.60 & 180.39 & 192.28 & 11.89 & 29.45 & 30.40 & 7.56 & 0.93 & 371.61 & 814.75 \\
\hline
\end{tabular}

$\mathrm{GCV}=$ genotypic coefficient of variation; $\mathrm{PCV}=$ phenotypic coefficient of variation; ECV = environmental coefficient of variation; $\mathrm{h}^{2}=$ heritability in broad

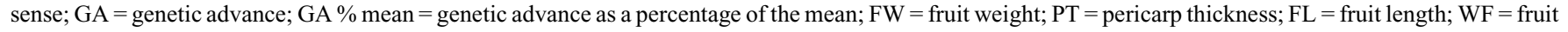
width; NFP = number of fruits per plant; YP = yield per plant; $\mathrm{CC}=$ capsaicin content.

Table 5. Phenotypic correlation between the seven traits evaluated in 11 genotypes $C$. chinense Jacq.

\begin{tabular}{|c|c|c|c|c|c|c|c|}
\hline Characteristics & FW (g) & PT $(\mathrm{cm})$ & $\mathrm{FL}(\mathrm{cm})$ & $\mathrm{WF}(\mathrm{cm})$ & NFP & YP (g/plant) & $\mathrm{CC}\left(\mathrm{mg} \cdot \mathrm{g}^{-1} \mathrm{DW}\right)$ \\
\hline$\overline{\mathrm{FW}(\mathrm{g})}$ & 1 & $0.492 * *$ & -0.070 & $0.662 * *$ & $-0.416^{* *}$ & $0.558 * *$ & $-0.484^{* *}$ \\
\hline PT $(\mathrm{cm})$ & & 1 & $-0.399 * *$ & $0.696 * *$ & $0.318^{*}$ & $0.770 * *$ & $-0.744 * *$ \\
\hline $\mathrm{FL}(\mathrm{cm})$ & & & 1 & $-0.573 * *$ & 0.171 & 0.063 & 0.042 \\
\hline $\mathrm{WF}(\mathrm{cm})$ & & & & 1 & -0.133 & $0.519 * *$ & $-0.436 * *$ \\
\hline NFP & & & & & 1 & $0.503 * *$ & $-0.314^{*}$ \\
\hline YP (g/plant) & & & & & & 1 & $-0.883 * *$ \\
\hline $\mathrm{CC}\left(\mathrm{mg} \cdot \mathrm{g}^{-1} \mathrm{DW}\right)$ & & & & & & & 1 \\
\hline
\end{tabular}

*,**Significant at $P<0.05$ or 0.01 , respectively.

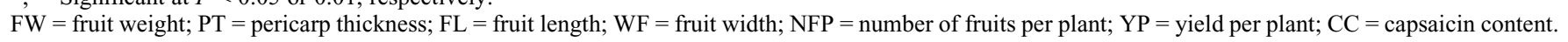

Table 6. Principal component analysis of eigenvalues and eigenvectors of seven characteristics evaluated instead of genotypes of $C$. chinense Jacq.

\begin{tabular}{lrrr}
\hline & $\mathrm{C} 1$ & $\mathrm{C} 2$ & $\mathrm{C} 3$ \\
\hline Eigenvalues & & & \\
Own values & 3.712 & 1.735 & 1.333 \\
\% Explained variance & 53.035 & 24.798 & $\mathbf{9 4 . 0 2 6}$ \\
\% Accumulated variance & 53.035 & 77.833 & \\
& & & 0.563 \\
Eigenvectors & & & -0.261 \\
FW (g) & 0.738 & 0.365 & 0.691 \\
PT (cm) & 0.916 & -0.044 & -0.165 \\
FL (cm) & -0.318 & -0.611 & -0.443 \\
WF (cm) & 0.802 & 0.468 & 0.110 \\
NFP & 0.197 & -0.864 & -0.188 \\
YP (g/plant) & 0.885 & -0.422 & 0.291 \\
CC (mg.g ${ }^{-1}$ DW) & -0.874 & & \\
\hline Cl & & & \\
\hline
\end{tabular}

$\mathrm{C} 1=$ principal component $1 ; \mathrm{C} 2=$ principal component $2 ; \mathrm{C} 3=$ principal component $3 ; \mathrm{FW}=$ fruit weight; $\mathrm{PT}=$ pericarp thickness; $\mathrm{FL}=$ fruit length; $\mathrm{WF}=$ fruit width; $\mathrm{NFP}=$ number of fruits per plant; $\mathrm{YP}=$ yield per plant; $\mathrm{CC}=$ capsaicin content.

variation, as determined by the variable NFP, which showed a significant positive influence on the formation of that component. The third component (C3) was determined by the variable FL, which extracted $16.19 \%$ of the total variation detected. Figure 1 shows the spatial distribution of the genotypes and the variables of the first two principal components (C1 and $\mathrm{C} 2$ ). Genotypes AKN-08 and ASBC09 were located in quadrant I and presented the highest values for YP and FW but the lowest values for NFP; genotypes RES-05 and MBI-11 were located in quadrant II, and genotype RNJ-04 was found in quadrant III. It is important to note that in these two quadrants, genotypes with the highest values of CC were found; however, they also presented lower values of YP, PT, and FW. Genotypes RKI-01, RHC-02, RHN-03, NBA-06, NKA-07, and MSB-12 were located in quadrant IV, and these presented high NFP, YP, and PT values.

Cluster analysis. The dendrogram obtained from the cluster analysis by creating a cut at a distance of 4.7 allowed the formation of six groups (A, B, C, D, E, and F) (Fig. 2) comprising the following genotypes: MBI-11 in A; MSB-12, RHN-03, and NKA-07 in B; RHC-02, RKI-01, and NBA06 in C; AKN-08 and ASBC-09 in D; RNJ-04 in E; and RES-05 in F. Table 7 shows the average values for the different characters evaluated based on the six groups generated for the cluster analysis. The genotypes (AKN-08 and ASBC-09) of group D presented the highest average values for FW, PT, and YP. The highest average values for CC were found in genotypes RNJ-04 and RES-05 of group $\mathrm{E}$ and group $\mathrm{F}$.

\section{Discussion}

In our study, the ANOVA revealed significant differences in characteristics among the 11 varieties. Similar results were reported by Verdugo et al. (2008), who worked with populations of Capsicum annuum, and by Mishra et al. (2015), who worked with
Curcuma longa L. Our results showed that genotype ASBC-09 had significantly superior $\mathrm{PT}, \mathrm{FW}, \mathrm{WF}$, and $\mathrm{YP}$ compared to the other genotypes evaluated. However, genotype RES-05 presented the highest CC value, which differed significantly from that of the other genotypes evaluated. Therefore, it can be considered a potential parent for obtaining varieties with higher $\mathrm{CC}$ in an improvement program, or it could be directly used for the extraction of capsaicin.

According to Rodríguez et al. (2008), the $\mathrm{CV}$ estimate provides the degree of variation in relation to the average of a given characteristic and shows the variability present within it, as well as its possibilities for improvement. This allows us to infer that the characteristics evaluated during our work were adequate for obtaining substantial advances in selection processes. Similar recommendations have been described by Mishra et al. (2015) and Thul et al. (2009). Our results showed a wide range of variation $(14.08 \%-94.50 \%)$ obtained in the values of $\mathrm{CV}$, for the characteristics evaluated. Mehmood et al. (2014), who performed a study of the genetic diversity of Pakistani guava (Psidium guajava L.) germplasm and its implications for conservation and breeding, reported extensive morphological variability, with a CV range between $15.62 \%$ and $44.3 \%$. In our work, the GCV and PCV estimates were higher for CC $(29.45 \%$ and $30.40 \%$, respectively) and NFP $(8.53 \%$ and $9.25 \%$, respectively). Similar results were reported by Choudhary and Samadia (2004), who worked with 30 chili genotypes and obtained high phenotypic and genotypic $\mathrm{CV}$ values for red ripe fruit yield per plant (44.20 and 42.91, respectively), followed by green fruit yield per plant, weight of seeds per fruit, FW, and NFP.

Our results showed high heritability for YP (0.98), CC (0.93), FW (0.91), and NFP (0.85). Similar results were reported by Do 


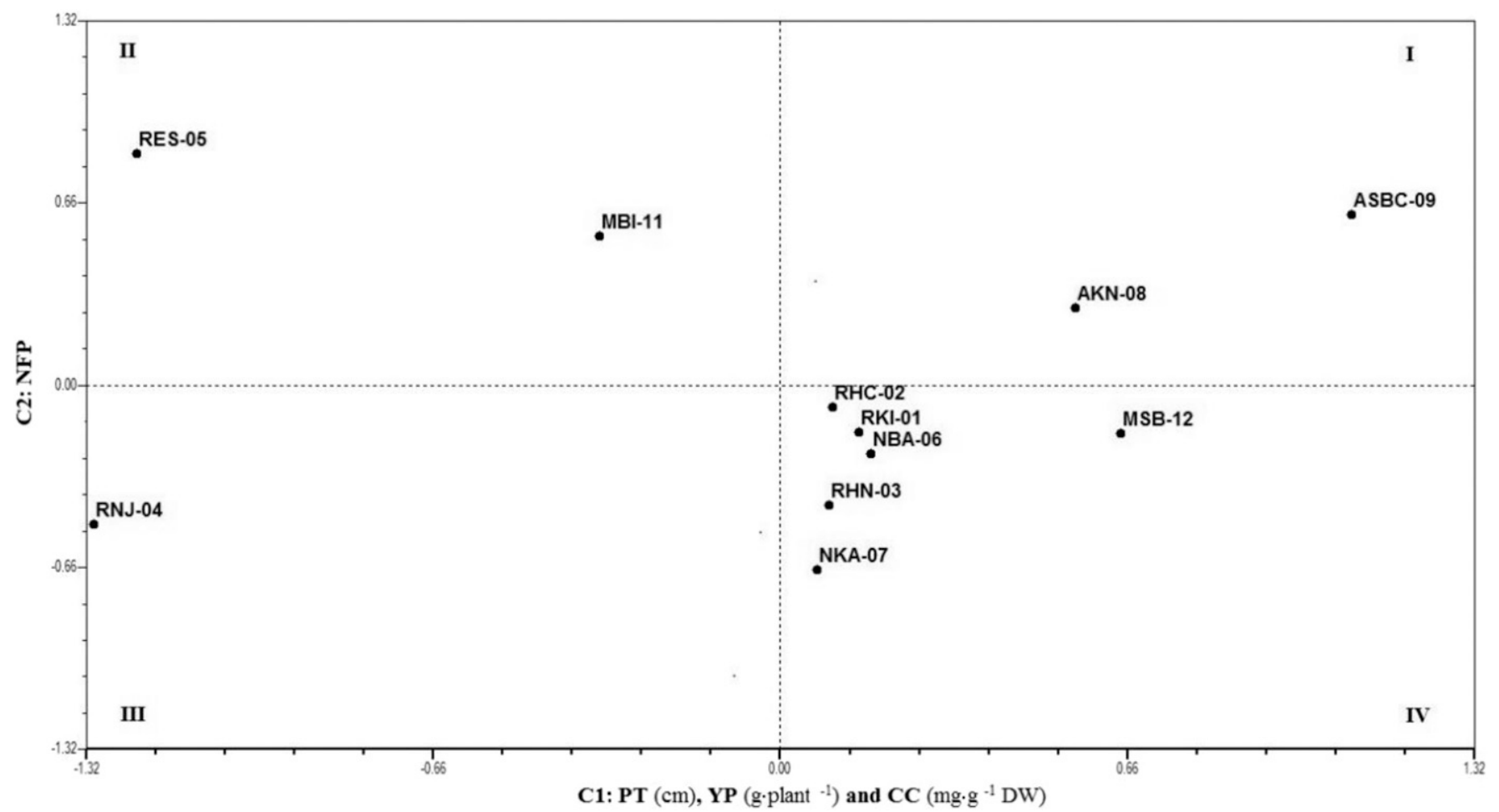

Fig. 1. Principal component analysis of 11 genotypes of $C$. chinense Jacq. based on seven characteristics evaluated and represented in two principal components $(\mathrm{C} 1: 53.03 \% ; \mathrm{C} 2: 24.79 \%)$. PT = pericarp thickness; NFP = number of fruits per plant; YP = yield per plant; CC = capsaicin content. Quadrants: I, II, III, and IV.

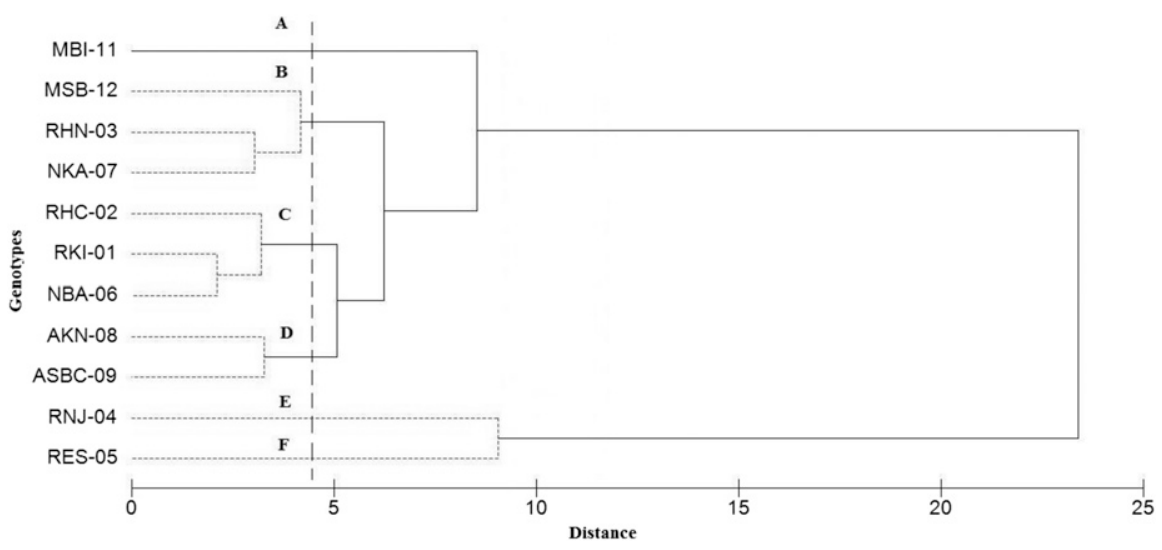

Fig. 2. Cluster analysis dendrogram according to UPGMA using the Euclidean distance coefficient to represent the grouping between genotypes of $C$. chinense Jacq.

Table 7. Comparison of the groups revealed by the cluster analysis using the respective averages of the seven characteristics evaluated for the genetic differentiation of $C$. chinense Jacq.

\begin{tabular}{lrcccccc}
\hline Groups & FW $(\mathrm{g})$ & PT $(\mathrm{cm})$ & FL $(\mathrm{cm})$ & WF $(\mathrm{cm})$ & NFP & YP $(\mathrm{g} / \mathrm{plant})$ & CC $\left(\mathrm{mg} \cdot \mathrm{g}^{-1} \mathrm{DW}\right)$ \\
\hline A & 13.53 & 0.19 & 4.24 & 2.95 & 105 & 1418.62 & 44.54 \\
B & 9.92 & 0.24 & 4.15 & 3.16 & $\mathbf{2 4 5}$ & 2408.43 & 23.68 \\
C & 13.18 & 0.22 & 4.67 & 3.03 & 179 & 2350.43 & 22.78 \\
D & $\mathbf{1 6 . 7 5}$ & $\mathbf{0 . 2 5}$ & 4.05 & $\mathbf{3 . 9 9}$ & 152 & $\mathbf{2 5 4 7 . 7 8}$ & 25.15 \\
E & 6.75 & 0.14 & $\mathbf{5 . 2 8}$ & 2.42 & 220 & 1482.28 & 120.38 \\
F & 7.77 & 0.16 & 3.63 & 2.97 & 109 & 846.78 & $\mathbf{1 4 7 . 1 1}$ \\
\hline
\end{tabular}

Bold numbers represent the highest value between groups.

$\mathrm{FW}=$ fruit weight $\mathrm{PT}=$ pericarp thickness; $\mathrm{FL}=$ fruit length $; \mathrm{WF}=$ fruit width; $\mathrm{NFP}=$ number of fruits per plant; $\mathrm{YP}=$ yield per plant; $\mathrm{CC}=$ capsaicin content.

Rêgo et al. (2011), who studied the phenotypic diversity in fruits of $C$. baccatum var. pendulum and obtained high $\mathrm{FW}$ values for $h^{2}(97.3 \%)$. The high values of GCV,$h^{2}$, and
GA obtained for YP, NFP, and CC in our study suggested that these characteristics are feasible for inclusion in a program of genetic improvement for Habanero pepper. High heritability and high GA have been reported for different characteristics of different species (Jatropha curcas L., Cicer arietinum L., Curcuma longa L.) (Mishra et al., 2015; Tripathi et al., 2012, 2013).

When analyzing the results of the calculations of correlations between characteristics, YP had a high positive correlation with PT $\left(0.770^{* *}\right)$, WF $\left(0.519^{* *}\right)$, FW $\left(0.558^{* *}\right)$, and NFP $\left(0.503^{* *}\right)$; these correlation values corresponded to the genotypes with greater yield (ASBC-09 and AKN-08). In a similar study performed by Sieczko et al. (2015), a positive correlation was found $(0.42)$ between fruit size and yield capacity.

The PCA results showed that the first three components extracted $94.02 \%$ of the total variation. In a similar study by Mehmood et al. (2014), who worked with Psidium guajava L., the PCA separated the 15 quantitative traits into six components, which explained $74.54 \%$ of the total variation of the PCA plot and successfully grouped the samples according to their phenotypic resemblance. However, the morphological dendrogram generated from agglomeration hierarchical clustering grouped the 132 accessions into three major clusters. Our results showed that the dendrogram obtained from the cluster analysis allowed the formation of six groups (A, B, C, D, E, and F). Group D (AKN-08 and ASBC-09) presented the highest average values for FW, PT, and YP, and group E (RNJ-04) and group F (RES-05) presented the highest average values for $\mathrm{CC}$; therefore, they can be recommended as progenitors in future genetic improvement 
work aiming to increase the pungency of genotypes with outstanding agronomic characteristics.

Thul et al. (2009) estimated the phenotypic divergence in a collection of Capsicum spp. for yield-related traits. They concluded that the three characteristics with the greatest roles in differentiation were fruit diameter, NFP, and leaf diameter, indicating that they can be used as conventional/morphological markers for the improvement of chili yield and obtaining good segregants in chili breeding programs.

As a result of our study, the PCA and cluster analysis showed that the genotypes studied are genetically divergent, which could facilitate the production of heterotic hybrids for the characteristics analyzed. These results concur with those obtained by Castañón-Nájera et al. (2008), who found considerable genetic diversity when using PCA and cluster analysis to evaluate the variation of characteristics related to yield in genotypes of Capsicum spp.

In conclusion, our results indicated that high values of phenotypic and genetic variation, heritability, and GA for all the characteristics evaluated confirmed significant variability between the genotypes of Habanero pepper, which allowed us to guarantee that these genotypes can be part of an improvement program. However, according to the results obtained from the PCA and cluster analysis, for the purpose of selecting and recommending progenitors to obtain hybrids of Habanero pepper (C. chinense Jacq.) with high yield and increased CC (pungency), it is recommended that the genotypes of group D (AKN-08 and ASBC-09) should be used as progenitors of the highest yield, and that cross-breeding with genotypes with the highest CC in group E (RNJ-04) and group F (RES-05) should be performed.

\section{Literature Cited}

Acquaah, G. 2009. Chapter 4: Introduction to quantitative genetics, p. 75-77. Principles of plant genetics and breeding. 2nd ed. John Wiley \& Sons, Blackwell, Oxford.
Baba, V.Y., K.R. Rocha, G.P. Gomes, C. de Fátima Ruas, P.M. Ruas, R. Rodrigues, and L.S.A. Gonçalves. 2016. Genetic diversity of Capsicum chinense accessions based on fruit morphological characterization and AFLP markers. Genet. Resources Crop Evol. 63(8):1371-1381.

Bhatia, R., S.S. Dey, and R. Kumar. 2017. Genetic divergence studies in tulip (Tulipa gesneriana L.). The Horticultural Society of India (Regd.) 74(4):562-567.

Castañón-Nájera, G., L. Latourerie-Moreno, M. Mendoza-Elos, A. Vargas-López, and H. CárdenasMorales. 2008. Colección y caracterización de Chile (Capsicum spp.) en Tabasco, México. Phyton 77:189-202.

Choudhary, B.S. and D.K. Samadia. 2004. Variability and character association in chilli landraces and genotypes under arid environment Indian J. Hort. 61(2):132-136.

Collins, M.D., L.M. Wasmund, and P.W. Bosland 1995. Improved method for quantifying capsaicinoids in Capsicum using high-performance liquid chromatography. HortScience 30:137-139.

Diario Oficial de la Federación (DOF). 2012. Norma Oficial Mexicana NOM-189-SCFI2012, Chile Habanero de la Península de Yucatán (Capsicum Chinense Jacq.). Especificaciones y métodos de prueba. 5 July 2017. $<\mathrm{http}: / /$ www.dof.gob.Mx $>$.

Do Rêgo, E.R., M.M. do Rêgo, C.D. Cruz, F.L. Finger, and V.W.D. Casali. 2011. Phenotypic diversity, correlation and importance of variables for fruit quality and yield traits in Brazilian peppers (Capsicum baccatum). Genet. Resources Crop Evol. 58(6):909-918.

IBM Corp. 2013. IBM SPSS Statistics for Windows, Version 22.0, Release 2013. IBM Corp., Armonk, NY.

IPGRI, AVRDC and CATIE. 1995. Descriptors for Capsicum (Capsicum spp.). International Plant Genetic Resources Institute, Rome, Italy; the Asian Vegetable Research and Development Center, Taipei, Taiwan, and the Centro Agronómico Tropical de Investigación y Enseñanza, Turrialba, Costa Rica. p. 28-38.

Mehmood, A., M.J. Jaskani, I.A. Khan, S. Ahmad, R. Ahmad, S. Luo, and N.M. Ahmad. 2014 Genetic diversity of Pakistani guava (Psidium guajava L.) germplasm and its implications for conservation and breeding. Scientia Hort. 172:221-232.

Mishra, R., A.K. Gupta, R.K. Lal, T. Jhang, and N. Banerjee. 2015. Genetic variability, analysis of genetic parameters, character associations and contribution for agronomical traits in turmeric
(Curcuma longa L.). Ind. Crops Prod. 76:204 208.

Pistorale, S.M., L.A. Abbott, and A. Andrés. 2008. Diversidad genética y heredabilidad en sentido amplio en agropiro alargado, Thinopyrum ponticum. Cienc. Investig. Agrar. 35(3):259264.

Rodríguez, Y., T. Depestre, and O. Gómez. 2008. Eficiencia de la selección en líneas de pimiento (Capsicum annuum), provenientes de cuatro sub-poblaciones, en caracteres de interés productivo. Cienc. Investig. Agrar. 35(1):37-49.

Rohlf, F.J. 2005. Numerical taxonomy and multivariate analysis system (NTSYS-pc) version 2.2. User guide. Exeter Software, NY.

Saoudi, W., M. Badri, M. Gandour, A. Smaoui, C. Abdelly, and W. Taamalli. 2016. Assessment of genetic variability among Tunisian populations of Hordeum marinum using morphoagronomic traits. Crop Sci. 57(1):302-309.

SAS Institute, Inc. 2003. SAS software release 9.1 for Windows. SAS Institute, Cary, NC.

Sieczko, L., A. Masny, K. Pruski, E. Żurawicz, and W. Maadry. 2015. Multivariate assessment of cultivars' biodiversity among the Polish strawberry core collection. Hort. Sci. 42(2):83-93.

Silva Cifuentes, E., F. Castillo González, J.D. Molina Galán, I. Benítez Riquelme, A. Santacruz Varela, and R. Castillo Torres. 2011. Selección de progenitores, varianzas genéticas y heredabilidad para acumulación temprana de sacarosa en caña de azúcar. Rev. Fitotec. Mex. 34(2):107-114.

Thul, S.T., R.K. Lal, A.K. Shasany, M.P. Darokar, A.K. Gupta, M.M. Gupta, and S.P.S. Khanuja 2009. Estimation of phenotypic divergence in a collection of Capsicum species for yieldrelated traits. Euphytica 168(2):189-196.

Tripathi, A., D.K. Mishra, and J.K. Shukla. 2013. Genetic variability, heritability and genetic advance of growth and yield components of Jatropha (Jatropha curcas Linn.) genotypes. Trees (Berl.) 27(4):1049-1060.

Tripathi, S., V. Sridhar, A.K. Jukanti, K. Suresh, B.V. Rao, C.L.L. Gowda, and P.M. Gaur. 2012. Genetic variability and interrelationships of phenological, physicochemical and cooking quality traits in chickpea. Plant Genet. Resources 10(3):194-201.

Verdugo, S.H., R.G.L. España, P.S. Peña, M.V. Romero, S.P. Terraza, F. Porras, and J.L.C. Madrid. 2008. Variación fenotípica entre y dentro de poblaciones silvestres de chile del noroeste de México. Rev. Fitotec. Mex. 31(4): $323-330$ 